\title{
BIBECHANA
}

ISSN 2091-0762 (Print), 2382-5340 (Online)

Journal homepage: http://nepjol.info/index.php/BIBECHANA

Publisher: Department of Physics, Mahendra Morang A.M. Campus, TU, Biratnagar, Nepal

\section{Prediction of daily global solar radiation using different empirical models on the basis of meteorological parameters at Trans Himalaya Region, Nepal}

\author{
Usha Joshi $^{1 *}$, I. B. Karki ${ }^{2}$, N.P. Chapagain ${ }^{3}$, K.N. Poudyal ${ }^{4}$ \\ ${ }^{1}$ Department of Physics, Patan Multiple Campus, TU, Patan, Nepal \\ ${ }^{2}$ Nepal Open University, Nepal \\ ${ }^{3}$ Department of Physics, Amrit Campus, TU, Kathmandu Nepal \\ ${ }^{4}$ Department of Physics, Pulchowk Campus, IOE, TU, Patan, Nepal \\ *Email: ushajoshik1967@gmail.com
}

\section{Article Information:}

Received: May 30, 2020

Accepted: August 9, 2020

Keywords:

Global solar radiation

Pyranometer

Meteorological parameters

Regression technique

Empirical constants

\begin{abstract}
Global Solar Radiation (GSR) is the cleanest and freely available energy resource on the earth. GSR was measured for six years (2010 -2015) at the horizontal surface using calibrated first class CMP6 pyranometer at Kathmandu (Lat. 27.70 $\mathrm{N}$, Long. $85.5^{\circ} \mathrm{E}$ and Alt. $\left.1350 \mathrm{~m}\right)$. This paper explains the daily, monthly and seasonal variations of GSR and also compares with sunshine hour, ambient temperature, relative humidity and precipitation to GSR. The annual average global solar radiation is about $4.16 \mathrm{kWh} / \mathrm{m}^{2} /$ day which is significant amount to promote solar active and passive energy technologies at Trans-Himalaya region. In this study, the meteorological parameters are utilized in regression technique for four different empirical models and finally the empirical constants are found. Thus obtained coefficients are utilized to predict the GSR using meteorological parameters for the years to come. In addition, the predicted GSR is found to be closer with measured value of GSR. The values are justified by using statistical tools such as coefficient of determination $\left(\mathrm{R}^{2}\right)$, root mean square error (RMSE), mean percentage error (MPE) and mean bias error (MBE). Finally, the values of $\mathrm{R}^{2}$, RMSE, MPE and MBE are found to be 0.792, 1.405, -1.014, and 0.011, respectively for model (D), which are based on sunshine hour, temperature and relative humidity. In this model, the empirical constants, $\mathrm{a}=0.155, \mathrm{~b}=0.134, \mathrm{c}=$ 0.014 and $\mathrm{d}=0.0007$ are determined which can be utilized at the similar geographical locations of Nepal.
\end{abstract}

DOI: https://doi.org/10.3126/bibechana.v18i1.29203

This work is licensed under the Creative Commons CC BY-NC License. https://creativecommons.org/licenses/by-nc/4.0/

\section{Introduction}

The sun is worshipped as god in Greek mythology.

The sun is source of various kinds of energies which has been proven vital from the beginning of human civilization till now. It is mainly composed of hydrogen (90\%), Helium and traces of other heavier elements. The fusion of hydrogen to helium 
is believed to be source of energy of sun by reducing mass almost 5 million tons per second in the form of electromagnetic radiation [1]. Approximately $95 \%$ of solar radiation lies within the wavelength range of 0.3-2.4 $\mu \mathrm{m}$, which comprises ultraviolet, visible and infrared portion of electromagnetic radiation, $1.2 \%$ lies in wavelength longer than $2.4 \mu \mathrm{m}$ and $3.6 \%$ lies in wavelength less than $2.4 \mu \mathrm{m}[1,2]$. Solar radiation reaching the earth surface gets through the constituents of the atmosphere. The earth's atmosphere consists of $\mathrm{O}_{2}, \mathrm{~N}_{2}, \mathrm{CO}_{2}, \mathrm{Ar}$ as permanent constituents. Water vapor and particulate matters such as dust, soot, water drops and ice crystals which vary spatially as temporary constituents. These constituents modify solar radiation arriving at the earth surface by scattering, reflection and absorption [2-4].

The radiation which evades absorption and scattering and arriving on ground directly in the line from the solar disk is called direct or beam radiation [3]. The radiation received from sun after its direction has been changed by scattering from atmosphere is diffused solar radiation. Consequently, the solar radiation arriving at the earth surface also known as global solar radiation(GSR) which is the sum of direct solar radiation and diffused solar radiation[3,4]. The GSR is of enormous importance as it can direct out development on low carbon trajectory [5]. Study on GSR is most essential in order to design and operate the solar energy devices. Hydrologists, engineers, agriculturists use solar radiation data for various purposes such as solar heating, cooking, drying, and interior illumination of buildings $[5,6]$. Also, manufacturers of solar equipment need to know the average GSR available in different and specific region. It is used to develop database in order to use it in active and passive energy form which could be a giant step for development of many sectors like tourism, education, industry, communication, health and scientific agriculture. One of the most used practical possibilities of renewable energy is the photovoltaic system to lighten the rural areas $[7,8]$. In Nepal, $83 \%$ of total population use clean energy and rest of them (22\%) live in live dark region [9]. Many people are still deprived of hydroelectricity, petroleum and so on. So people are forced to use kerosene lamp as an alternative to electricity. In Nepal, $87 \%$ of total energy is consumed in residential areas, 6\% in transportation, and $5 \%$ in industry. In FY 2017/18, the consumption of traditional, commercial and renewable energies are $70 \%, 27.8 \%$ and $2.2 \%$ of the total energy respectively. The above data shows that the large percentage of consumption of traditional energy is not environment friendly and unsustainable. It creates indoor and outdoor air pollution. The consumption of imported petroleum product has increased by $5.6 \%$ as compared to previous year and huge amount of hard earned foreign currency is used to fulfil this energy demand [9].

Nepal lies at most favorable solar belt in global map. Hence, Nepal receives sufficient and adequate amount of solar radiation throughout the country. The range of solar insolation and sunny days are $3.6-6.2 \mathrm{kWhr} / \mathrm{m}^{2} /$ day and about 300 days in a year [10]. The annual average sunshine hour and solar insolation are 6.8 hour/day and $4.23 \mathrm{kWhr} / \mathrm{m}^{2} /$ day respectively [11]. The solar irradiance at eastern highland is lesser than central mid-hill region and western hill of Nepal. This is because of higher range of humidity, precipitation and wind at the eastern part than at western part of Nepal [12].

The reliable and genuine information regarding the solar radiation for particular site can be applied in various field like hydrology, modern agriculture, solar active and passive energy, irrigation system and climate change. Further, specific understanding on GSR is required to design solar energy system. Even though we have necessity of solar radiation data, only few number of measuring equipment are available due to financial constraints and maintenance. So, we have to rely on several models to estimate the solar radiation based on the easily available meteorological parameters [8]. 
The commonly used empirical models to estimate solar radiation using sunshine hour with varying degree of complexity is followed by classical work of Angstrom and Prescott [13,14].So far various models have been developed by a number of researchers with different regression coefficients depending on meteorological parameters and locations. [7,8,15,16]. Estimation of GSR using temperature and precipitation for year 2005 and 2007, using RadEst 3.0 software was observed [17]. Similarly, estimation of GSR using empirical model based on sunshine hour, temperature and relative humidity (Abdalla Model) for four different places of Nepal has been done [18].

The available literature shows that there is limited study of solar radiation in Nepal. That is why it is necessary to develop authentic empirical constants on the basis of meteorological parameters such as temperature, sunshine hour and relative humidity. This is due to deficiency of solar energy data and lack of sense of importance of solar energy technique. In addition that, the empirical constants should be developed for every $200 \mathrm{~m}$ altitude because of abruptly varying geographical structure as well as complex terrain with variation of altitude (60m-8848m).

Different types of empirical models are used to estimate daily average solar radiation using meteorological parameters for different locations of Nepal. Thus found empirical constants are used to predict global solar radiation. The better performing model are those models, using sunshine duration [6, 13, 14]. The main focus of this research is to validate the performance of four empirical models based on temperature, relative humidity and sunshine hour.

\section{Methodology}

\section{Description of site}

Kathmandu Valley is capital city, and a hub of cultural as well as historical heritage, inhabited by 2.5 million people. It lies at $27.70^{\circ} \mathrm{N}$ and $85.5^{\circ} \mathrm{E}$ at mean elevation of about $1350 \mathrm{~m}$ from sea level [19, 20]. It is characterized by subtropical cool temperate climate where temperature normally varies from a minimum of $2.4^{\circ} \mathrm{C}$ for January to maximum of $35^{\circ} \mathrm{C}$ for June with annual average of mean temperature normal of $18.4^{\circ} \mathrm{C}$. The annual average of precipitation normal is $1454.8 \mathrm{~mm}$, most of which falls during monsoon [21, 22].

The data of hourly solar radiation on horizontal surface for Kathmandu were collected from archives of the Department of Hydrology and Meteorology, Government of Nepal (DHM/GoN) for the year 2010 to 2015. Daily data of Sunshine hour, maximum temperature, minimum temperature and relative humidity for the site were obtained from DHM/GoN. The GSR were measured using first class CMP6 Pyranometer [23].

\section{Theory}

$\mathrm{H}_{\mathrm{g}}\left(\mathrm{MJ} / \mathrm{m}^{2} /\right.$ day $)$ is the measured global solar radiation at the ground surface. $\mathrm{H}_{\mathrm{o}}$ is Extraterrestrial GSR which is found at the top of atmosphere of site measured in $\left(\mathrm{MJ} / \mathrm{m}^{2} /\right.$ day $)$.It is calculated theoretically as [3]

$$
\begin{array}{r}
H o=\frac{24}{\pi} I_{s c}\left[1+0.033 \cos \frac{360 n_{d}}{365}\right] \times \\
{[\cos \emptyset \cos \delta \sin \omega+\omega \sin \emptyset \sin \delta]}
\end{array}
$$

where, $I_{S c}$ is the solar constant which is given as,

$I_{S C}=\frac{1367 \times 3600}{10^{6}} \mathrm{MJ} / \mathrm{m}^{2} /$ day

where, $n_{d}$ is the day of the year, Julian days starting from January $1^{\text {st }}\left(n_{d}=1\right)$ to December $31^{\text {th }}\left(n_{d}\right.$ $=365)$. $\omega$ is hour angle, $\varnothing(\mathrm{rad})$ being latitude and $\delta(\mathrm{rad})$ is the declination angle whose expressions are given as,

$\delta=23.45 \sin \left[\frac{360}{365}\left(284+n_{d}\right)\right]$

and hour angle is,

$\omega=\cos ^{-1}[-\tan \varnothing \tan \delta]$

The relation of day length, the maximum feasible sunshine length for given day is given by equation,

$\operatorname{Daylength}(N)=\frac{2}{15} \omega=\frac{2}{15} \cos ^{-1}[-\tan \emptyset \tan \delta]$ 
There are many empirical models to estimate solar radiation reaching the earth's surface. Among them, in this research work the empirical models are selected on the basis of availability of meteorological parameters for given sites are listed in Table 1.

The solar radiation data which are analyzed to check the performance of above models consist of daily average global solar radiation for Kathmandu for year (2010 - 2015). The regression technique for the models used were performed by using Matlab2015Rb and advanced Microsoft Excel software analysis. The graph is obtained with help of Origin software as well as Matlab. We obtained statistical errors such as root mean square error (RMSE), mean percentage error (MPE), mean bias error (MBE) and coefficient of determination $\left(\mathrm{R}^{2}\right)$ to validate the efficiency of used model.

\section{Results and Discussion}

The correlation of daily GSR and clearness index $\left(\mathrm{K}_{\mathrm{T}}\right)$ with relative sunshine hour, difference of ambient temperature and relative humidity is shown in Table 2. It shows that the clearness index on average is more correlated than GSR with given parameters. Thus, the above four empirical models are utilized to predict the GSR at this region.

Empirical constants are found by using regression technique, and those values are used for the estimation of daily GSR from different models for different years at trans-Himalaya region separately. The estimated GSR were compared with corresponding value of measured radiation. To analyze the validity of used models we perform different statistical test. The statistical indices employed in all applied models are MPE, MBE, RMSE and coefficient of determination $\left(\mathrm{R}^{2}\right)$. The outcomes of these statistical analysis and values of empirical constants are mentioned in Table 3.

In the study for the determination of GSR, we have taken various single and multiple meteorological parameter models. Among those models, model D is multiple parameter model of sunshine hour, difference of temperature and average relative humidity which perform better than other models and indicates least value of RMSE, MPE, MBE and highest value of coefficient of determination.

The linear variation of monthly average measured and estimated GSR is shown in Fig. 1 for model D for different year. It shows that there is remarkable agreement between monthly average daily GSR for different years for model D with highly acceptable value of coefficient of determination.

Fig: 2 shows monthly variation of GSR from 2010 to 2015. The GSR gradually increases from December to May and sharply decrease due to high frequency of rainfall as well as cloudy days in June, July, and August till September. Above graph shows the value of global solar radiation received is maximum in the month of May, it is mainly due to less cloud, slow wind, less rainfall and less solar zenith angle. However, the normal trend deviates for the months of June, July and August for all the studied sites due to the fact that maximum rainfall of the year occurs in these months. In addition, lower values of GSR is found in winter season for the year 2010 to 2014. Moreover, there is lower values of GSR found during August for the year 2015.

Fig: 3(a), (b), (c), and (d) gives the variation of GSR and maximum temperature with month. There is close agreement between maximum temperature and GSR. In June, July and August, summer season although temperature is high, there is decrease of GSR due to heavy rainfall and cloudy sky.

Fig: 4 (a), (b), (c) and (d) show variation of GSR and relative humidity with month. There is opposite relation between GSR and relative humidity. In these figures, there is minimum relative humidity and higher GSR in May due to dry season. However, in rainy season, there is higher relative humidity and lower GSR which is usual practice in weather. 
Table 1: List of models used for the determination of global solar radiation.

\begin{tabular}{|c|c|c|l|}
\hline Model & Symbol & Parameters & \multicolumn{1}{|c|}{ Relation } \\
\hline Angstrom-Prescott Model [14, 15] & $\mathrm{A}$ & $\mathrm{n}, \mathrm{N}$ & $\frac{H_{g}}{H_{o}}=a+b\left(\frac{n}{N}\right)$ \\
\hline Swarthman-Oguniada Model [21] & $\mathrm{B}$ & $\mathrm{n}, \mathrm{N}, \mathrm{RH}$ & $\frac{H_{g}}{H_{o}}=a+b\left(\frac{n}{N}\right)+c(R H)$ \\
\hline Modified Angstrom Model & $\mathrm{C}$ & $\mathrm{n}, \mathrm{N}, \Delta \mathrm{T}$ & $\frac{H_{g}}{H_{o}}=a+b\left(\frac{n}{N}\right)+c(\Delta \mathrm{T})$ \\
\hline Modified Angstrom Model & $\mathrm{D}$ & $\mathrm{n}, \mathrm{N}, \Delta \mathrm{T}, \mathrm{RH}$ & $\frac{H_{g}}{H_{o}}=a+b\left(\frac{n}{N}\right)+c(\Delta T)+d(R H)$ \\
\hline
\end{tabular}

Table 2: Correlation of GSR and clearness index with given parameters.

\begin{tabular}{ccccc|cccc}
\hline \multirow{2}{*}{ Variables } & \multicolumn{3}{c|}{ Hg relate with variables for year } & \multicolumn{4}{c}{$\mathrm{K}_{\mathrm{T}}$ relate with variables for year } \\
\cline { 2 - 10 } & 2010 & 2012 & 2014 & 2015 & 2010 & 2012 & 2014 & 2015 \\
\hline $\mathrm{n} / \mathrm{N}$ & 0.2417 & 0.2921 & -0.0041 & 0.7066 & 0.607 & 0.7638 & 0.4896 & 0.811 \\
$\Delta \mathrm{T}$ & 0.1435 & 0.2473 & 0.0731 & 0.6174 & 0.5845 & 0.6193 & 0.4532 & 0.7784 \\
$\mathrm{RH}$ & -0.6278 & -0.491 & -0.3686 & -0.4095 & -0.5593 & -0.3401 & -0.1508 & -0.1443 \\
\hline
\end{tabular}

Table 3: Statistical indicators and empirical constants for empirical models used in research for different year using daily measured data. (Optimal values are bold-faced).

\begin{tabular}{|c|c|c|c|c|c|c|c|c|c|}
\hline \multirow[b]{2}{*}{ Year } & \multirow[b]{2}{*}{ Model } & \multicolumn{4}{|c|}{ Statistical Tools } & \multicolumn{4}{|c|}{ Empirical Constants } \\
\hline & & MPE (\%) & $\begin{array}{c}\mathrm{MBE} \\
\left(\mathrm{MJ} / \mathrm{m}^{2} / \mathrm{da}\right. \\
\mathrm{y})\end{array}$ & $\begin{array}{c}\text { RMSE } \\
(\mathrm{MJ} / \mathrm{m} 2 / \\
\text { day })\end{array}$ & $\mathrm{R}^{2}$ & $\mathrm{a}$ & $\mathrm{b}$ & $\mathrm{c}$ & $d$ \\
\hline \multirow{4}{*}{2015} & A & -7.559 & 0.278 & 2.705 & 0.587 & 0.118 & 0.566 & & \\
\hline & B & -7.593 & 0.262 & 2.706 & 0.586 & 0.065 & 0.573 & 0.001 & \\
\hline & $\mathrm{C}$ & -5.056 & 0.204 & 2.363 & 0.684 & -0.017 & 0.364 & 0.018 & \\
\hline & $\mathrm{D}$ & -4.871 & 0.148 & 2.310 & 0.698 & -0.191 & 0.363 & 0.020 & 0.002 \\
\hline \multirow{4}{*}{2014} & A & & 0.057 & 2.282 & 0.563 & 0.337 & 0.221 & & \\
\hline & B & -3.582 & 0.051 & 2.281 & 0.564 & 0.323 & 0.225 & 0.0002 & \\
\hline & $\mathrm{C}$ & -3.367 & 0.049 & 2.235 & 0.581 & 0.299 & 0.154 & 0.006 & \\
\hline & $\mathrm{D}$ & -3.277 & -0.013 & 2.179 & 0.602 & 0.134 & 0.148 & 0.009 & 0.002 \\
\hline \multirow{4}{*}{2012} & A & -4.911 & 0.007 & 2.885 & 0.606 & 0.295 & 0.414 & & \\
\hline & B & -4.907 & 0.011 & 2.884 & 0.606 & 0.303 & 0.412 & 0.0001 & \\
\hline & $\mathrm{C}$ & -4.837 & 0.006 & 2.873 & 0.609 & 0.282 & 0.386 & 0.002 & \\
\hline & D & -4.824 & -0.003 & 2.870 & 0.610 & 0.254 & 0.383 & 0.003 & 0.0002 \\
\hline \multirow{4}{*}{2010} & A & -3.584 & -0.180 & 2.969 & 0.684 & 0.348 & 0.299 & & \\
\hline & B & -3.058 & -0.040 & 2.740 & 0.731 & 0.681 & 0.213 & -0.004 & \\
\hline & $\mathrm{C}$ & -3.410 & -0.219 & 2.972 & 0.683 & 0.306 & 0.197 & 0.007 & \\
\hline & D & -3.005 & -0.070 & 2.759 & 0.727 & 0.636 & 0.167 & 0.004 & -0.003 \\
\hline \multirow{4}{*}{$\begin{array}{c}\text { all } \\
\text { Daily } \\
\text { average }\end{array}$} & A & -1.525 & 0.089 & 1.628 & 0.720 & 0.325 & 0.272 & & \\
\hline & B & -1.439 & 0.125 & 1.578 & 0.737 & 0.429 & 0.254 & -0.001 & \\
\hline & $\mathrm{C}$ & -1.025 & 0.039 & 1.408 & 0.791 & 0.229 & 0.140 & 0.013 & \\
\hline & D & -1.014 & 0.011 & 1.405 & 0.792 & 0.155 & 0.134 & 0.014 & 0.0007 \\
\hline
\end{tabular}




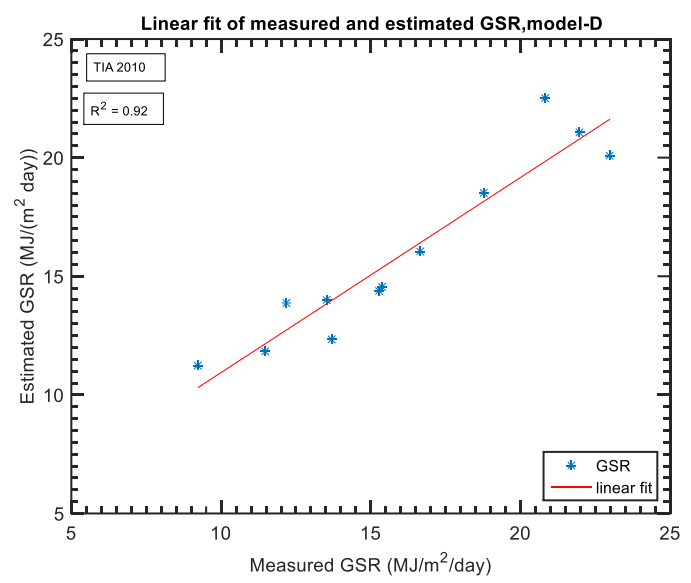

(a)

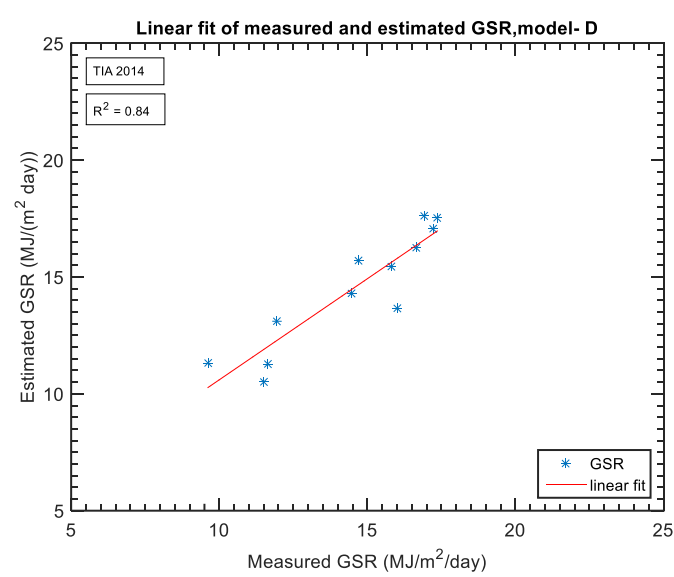

(c)

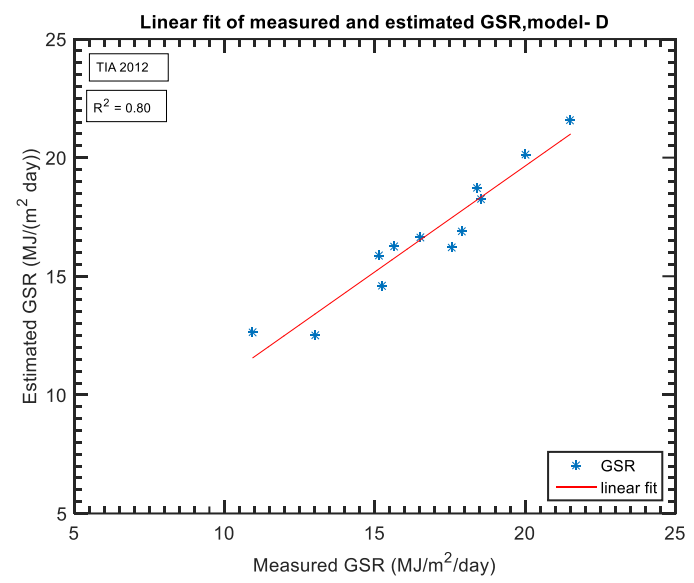

(b)

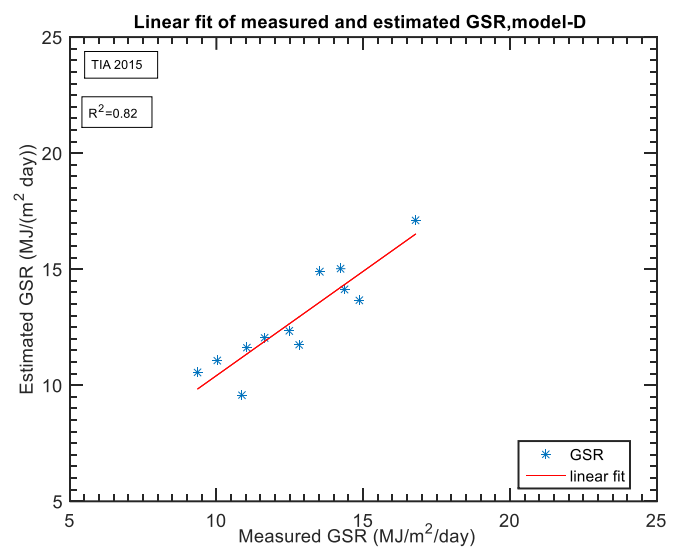

(d)

Fig. 1: Linear variation of monthly average measured and estimated GSR at Kathmandu Valley

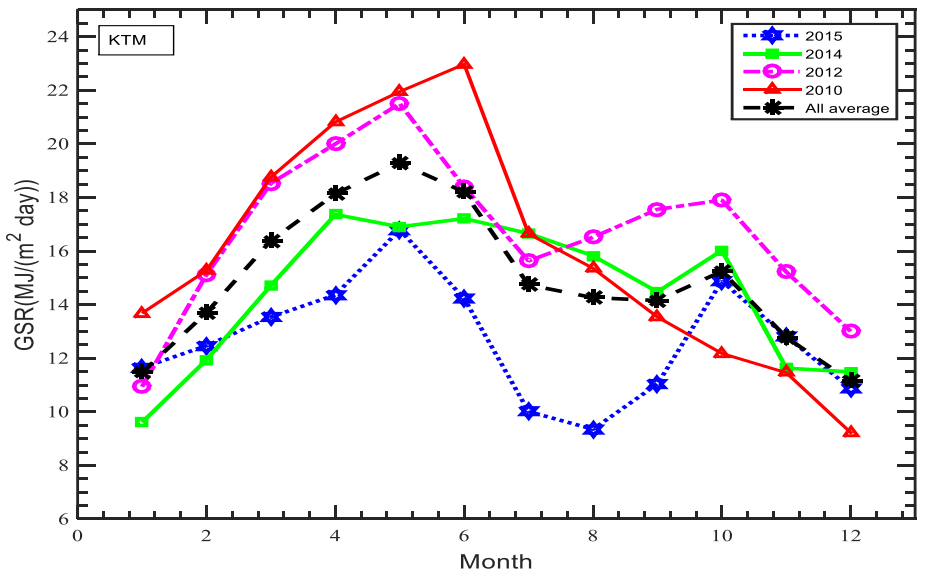

Fig. 2: Monthly variation measured GSR at Kathmandu Valley for the years (2010-2015). 


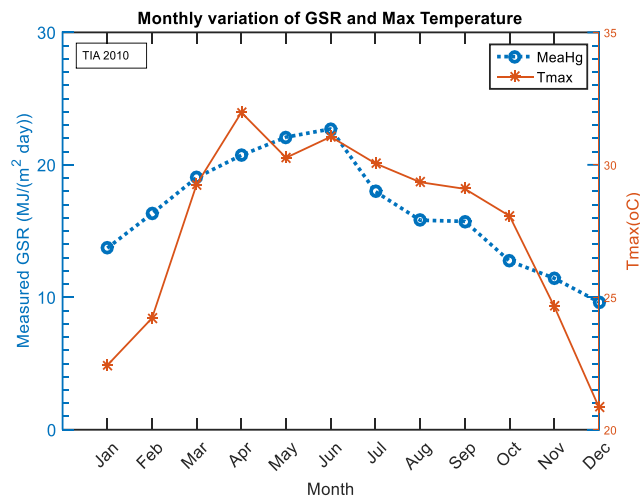

(a)

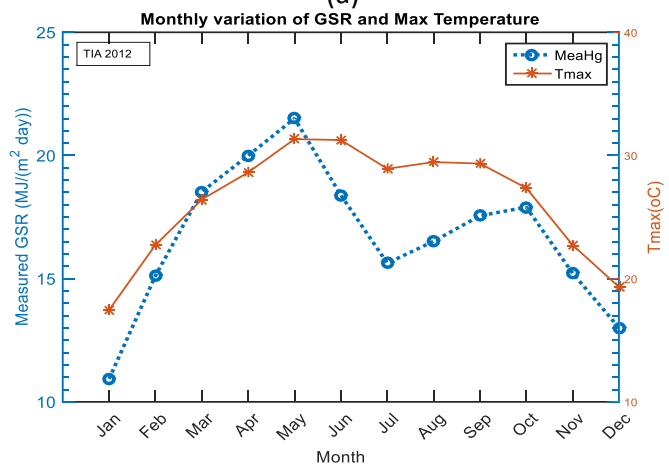

(b)

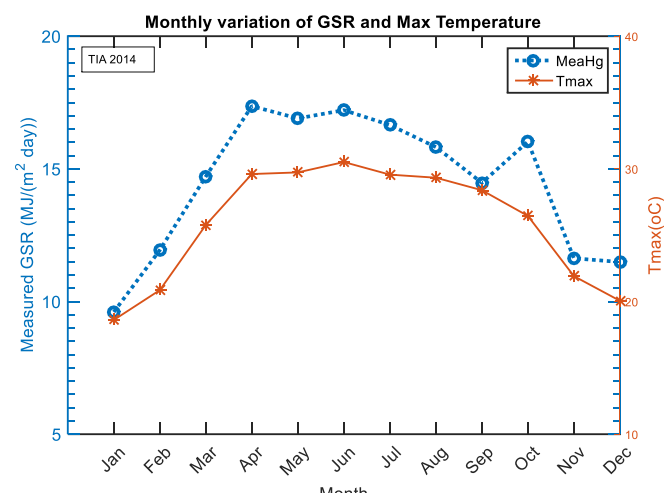

(c)

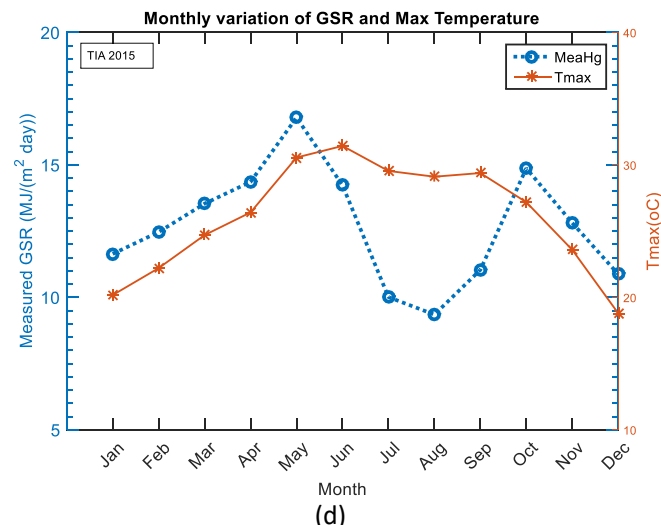

Fig 3: Monthly variation of GSR and maximum temperature at Kathmandu Valley for the years (2010, 2012, 2014, 2015).

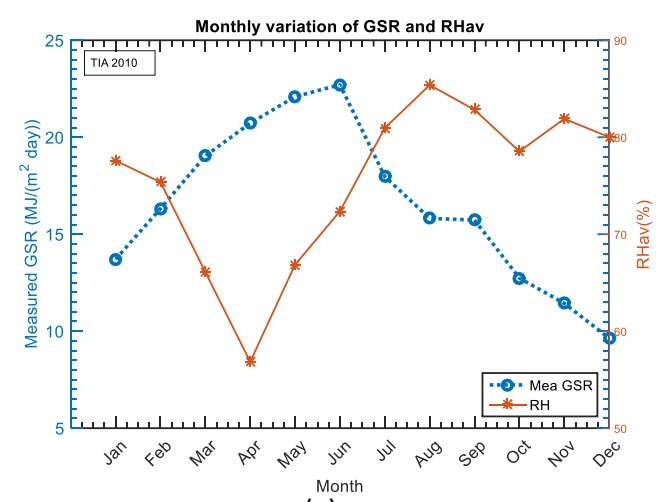

(a)

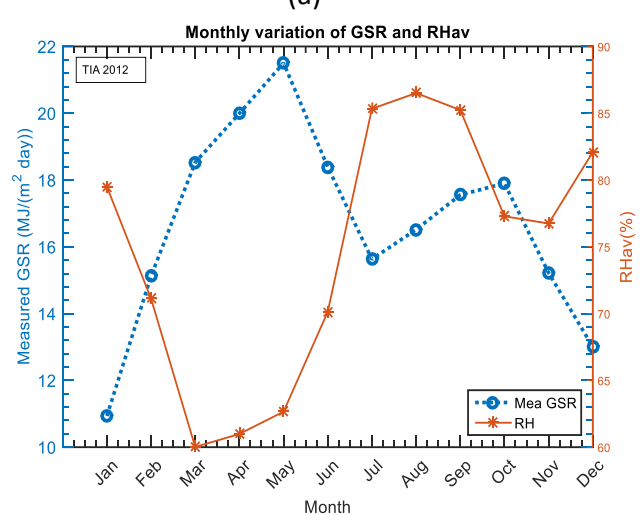

(b)

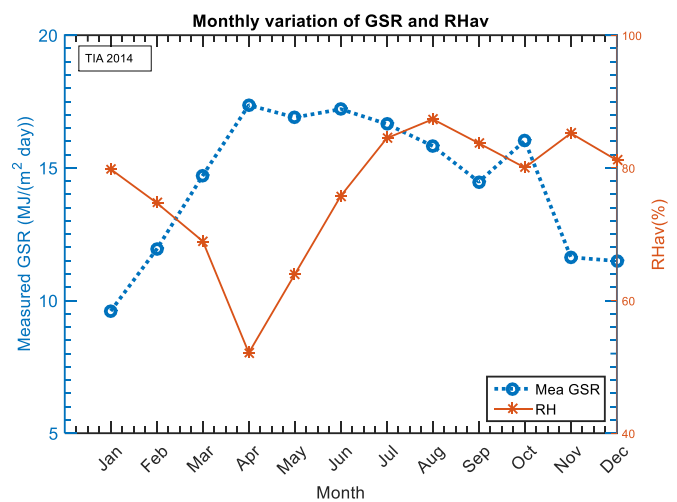

(c)

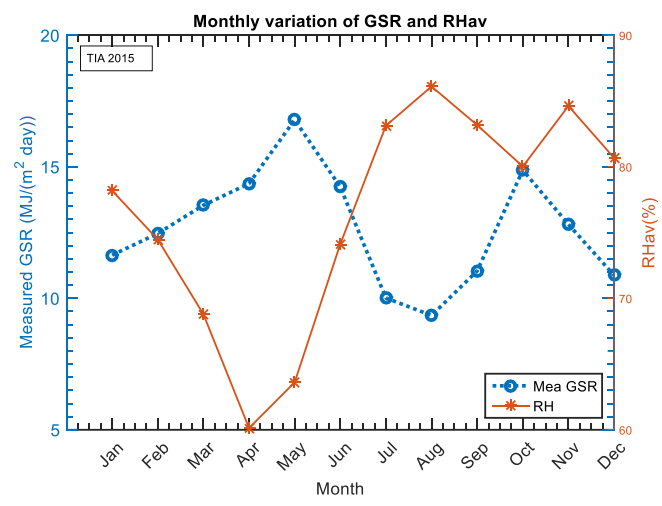

(d)

Fig. 4: Monthly variation of GSR and average relative humidity at Kathmandu Valley for the years (2010, 2012, 2014, 2015). 


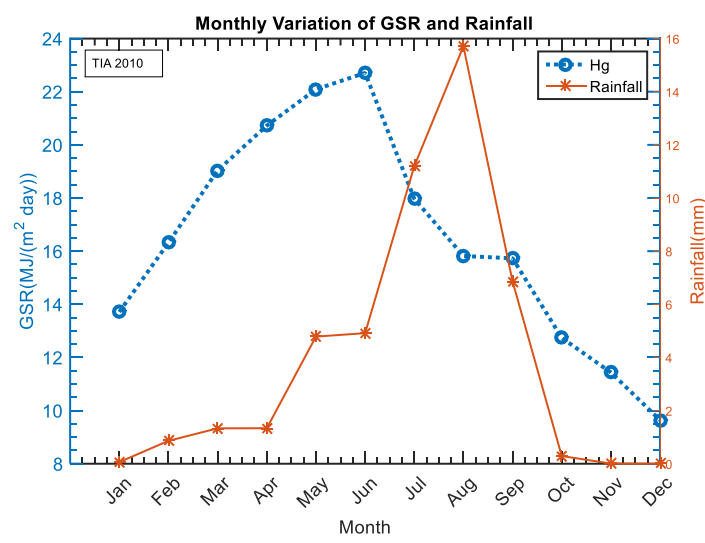

(a)

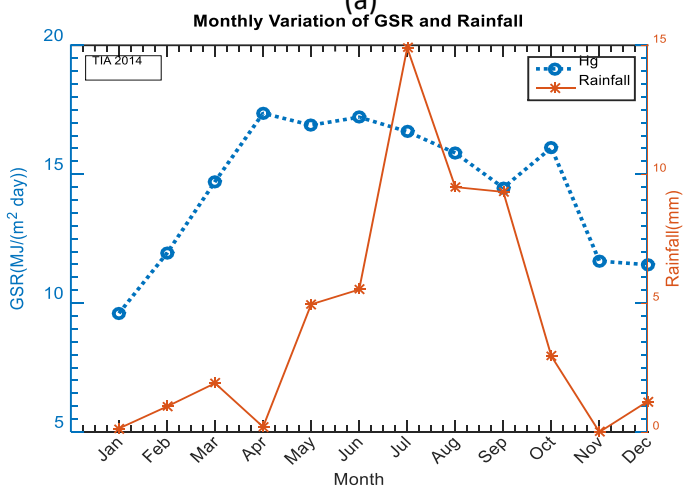

(c)

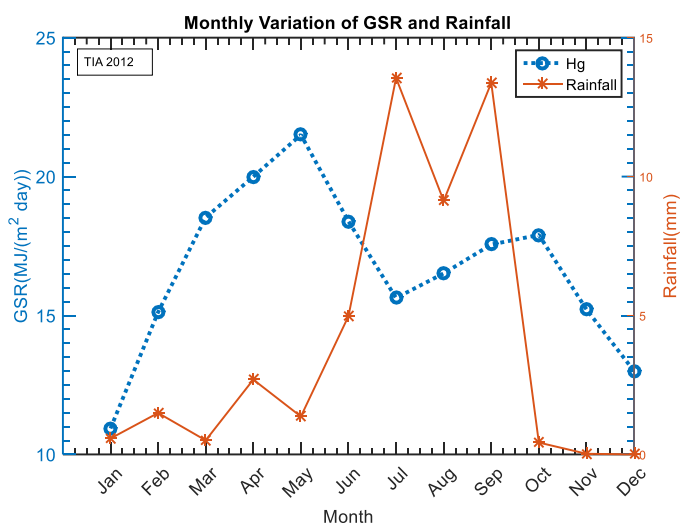

(b)

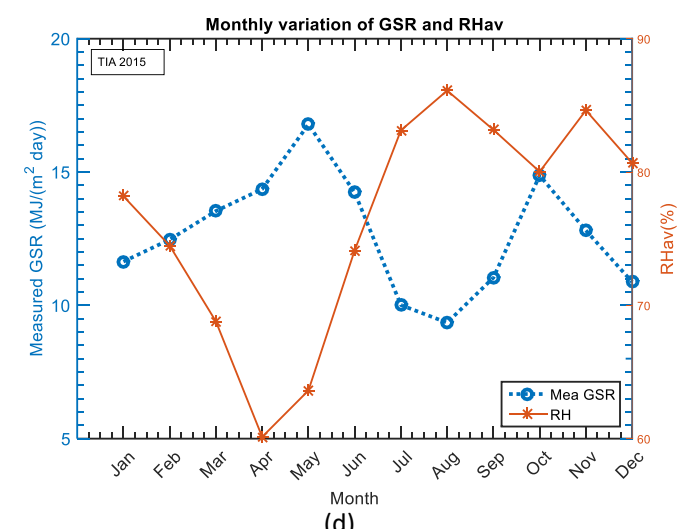

Fig 5: Monthly variation of GSR and rainfall at Kathmandu Valley (2010, 2012, 2014, 2015).

Fig: 5(a), (b), (c), and (d) shows variation of GSR and precipitation with month. Among the four figures rain fall is maximum in July, August and September in Fig 5(a), (c) and (d). However in Fig (b) rainfall is lower in August. At this time, there is lesser GSR due to local weather condition. In the summer or monsoon season the average rainfall is about $70 \%$ to $90 \%$ of whole year and remaining months remain almost dry. Hence normal trend deviate for these months [24].

The maximum and minimum value of GSR are $16.79 \pm 3.9 \mathrm{MJ} / \mathrm{m}^{2} /$ day and $9.35 \pm 3.08 \mathrm{MJ} / \mathrm{m}^{2} /$ day in May and August respectively for year 2015. Similarly, the monthly average GSR is maximum in May is $22.97 \pm 4.59 \mathrm{MJ} / \mathrm{m}^{2} /$ day and minimum in December is $9.22 \pm 1.74 \mathrm{MJ} / \mathrm{m}^{2} /$ day for year 2010 . The clearness index in July and August is low (0.25) and for those months GSR is $((10.01 \pm 3.75)$ and $(9.35 \pm 3.08) \mathrm{MJ} / \mathrm{m}^{2} /$ day) respectively. The lower value of GSR in this month is due to frequent rain fall in monsoon season. It is mainly due to less cloud, slow wind, less rainfall and less solar zenith angle. However, the normal trend deviates for the months of June, July and August for all the studied sites due to the fact that they are rainy seasons for the site and maximum rainfall of the year occurs in these months. In table 4, total and average GSR is lower in year 2015 and more rainfall in same year. In rainy season, sky is covered by cloud and this reduces the solar radiation reaching the ground surface. Not only the meteorological factors such as rainfall, sunshine duration and temperature affect the global solar radiation but also astronomical, geometrical and physical.

Fig: 6, shows the comparative study of seasonal variation of GSR at four different years at Kathmandu Valley. In the figure the maximum and minimum GSR is found at spring and winter season 
respectively. However, there is maximum fluctuation of GSR at summer season, it happens due to the presence of clouds and more rain fall during this time. In figure, standard deviation is used to compare the fluctuations in GSR. Among the years 2015 has less GSR than others.

Fig. 7,8 shows the variation of GSR and Clearness index with years in box plot. In year 2015 GSR is lower $\left(12.662 \pm 4.21 \mathrm{MJ} / \mathrm{m}^{2} /\right.$ day $)$ than in other year. It also seen from Table 3. In year 2015, Clearness index or transmittance of atmosphere is also low due to more rainfall. In 2015, GSR is slightly overestimated likewise for the year 2014, 2012, 2010 there is gradual increase in underestimation, it is due to variation of rainfall pattern and local weather condition. Due to the earthquake in Nepal (April 25, 2015, Saturday), the air pollutants escalated, which reduced the clearness index $\left(\mathrm{K}_{\mathrm{T}}\right)$ and as a result lower global solar radiation.

The prediction of GSR for 2017 for Kathmandu and Khumaltar is observed from empirical constants obtained from above analysis shown in Fig.9. The empirical constants for model E-19, $\mathrm{a}=$ $0.115, b=0.134, c=0.014$ and $d=0.0007$, is used for prediction. The predicted values are slightly less than observed values for Kathmandu for the month March, June and October as it depends upon meteorological parameters. The yearly predicted average value of GSR for Kathmandu and Khumaltar is14.56 MJ/m²/day and 14.16 $\mathrm{MJ} / \mathrm{m}^{2} /$ day for year 2017 . The total predicted yearly GSR for Kathmandu and Kumaltar are 5315.16 $\mathrm{MJ} / \mathrm{m}^{2} /$ day and $5169.78 \mathrm{MJ} / \mathrm{m}^{2} /$ day respectively.

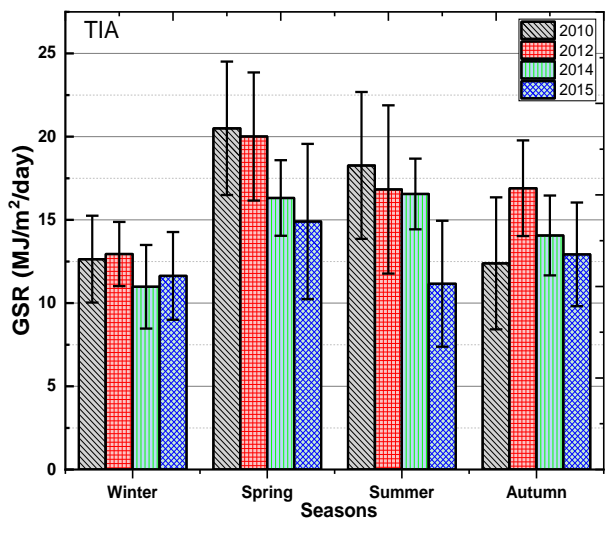

Fig 6: Seasonal variation of GSR at Kathmandu for year (2010-2015).

Table 4: Variation of GSR and rain fall in different year at Kathmandu Valley.

\begin{tabular}{|c|c|c|c|c|}
\hline Year & 2015 & 2014 & 2012 & 2010 \\
\hline $\begin{array}{l}\text { yearly mean GSR } \\
\left(\mathrm{MJ} / \mathrm{m}^{2} / \text { day }\right)\end{array}$ & $12.662 \pm 4.21$ & $14.499 \pm 3.45$ & $16.683 \pm 4.6$ & $16.033 \pm 5.7$ \\
\hline $\begin{array}{l}\text { Yearly total GSR } \\
\left(\mathrm{MJ} / \mathrm{m}^{2} / \text { day }\right)\end{array}$ & $4621.594 \pm 0.22$ & $5292.228 \pm 0.18$ & $6105.823 \pm 0.24$ & $5852.224 \pm 0.3$ \\
\hline $\begin{array}{l}\max \text { GSR } \\
\left(\mathrm{MJ} / \mathrm{m}^{2} / \text { day }\right)\end{array}$ & 22.23 - May 4 & 19.97-8 May & 26.99 - 13 May & 30.533- Sep 26 \\
\hline $\begin{array}{l}\min \text { GSR } \\
\left(\mathrm{MJ} / \mathrm{m}^{2} / \text { day }\right)\end{array}$ & 1.43 - March 1 & $4.65-\operatorname{Dec} 16$ & 2.95 -July 13 & $0.026-\operatorname{Sep} 29$ \\
\hline $\begin{array}{l}\text { Total rain } \\
(\mathrm{mm})\end{array}$ & 1649.4 & 1579.7 & 1465.94 & 1480.9 \\
\hline $\begin{array}{l}\max \text { Rain } \\
(\mathrm{mm})\end{array}$ & 115.5 - May 11 & $93.1-$ Jul 1 & $75 \mathrm{~mm}$ - Sep 14 & 80.7 - Jul 22 \\
\hline
\end{tabular}




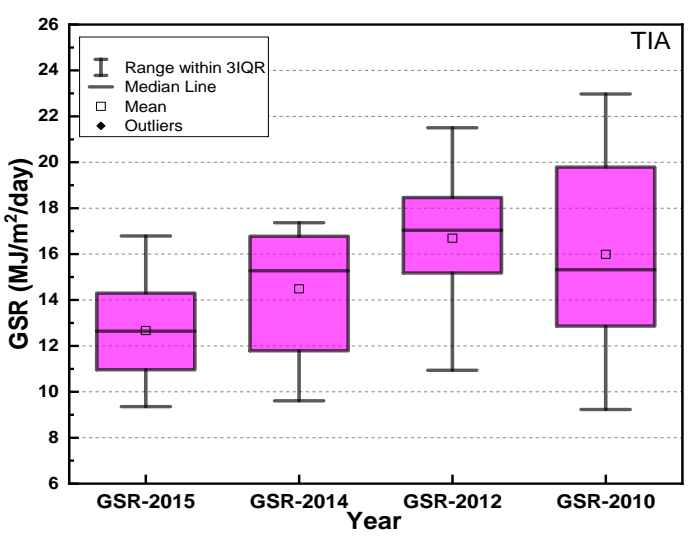

Fig. 7: Yearly variation of GSR for different year for given location

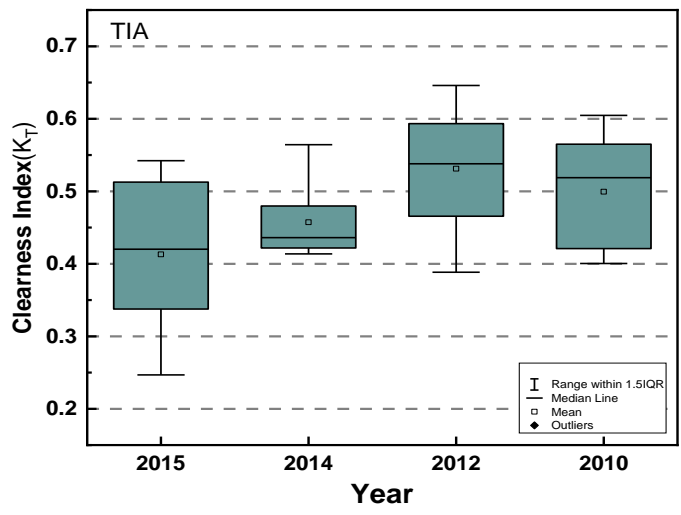

Fig. 8: Variation of clearness index for different year at Kathmandu Valley.

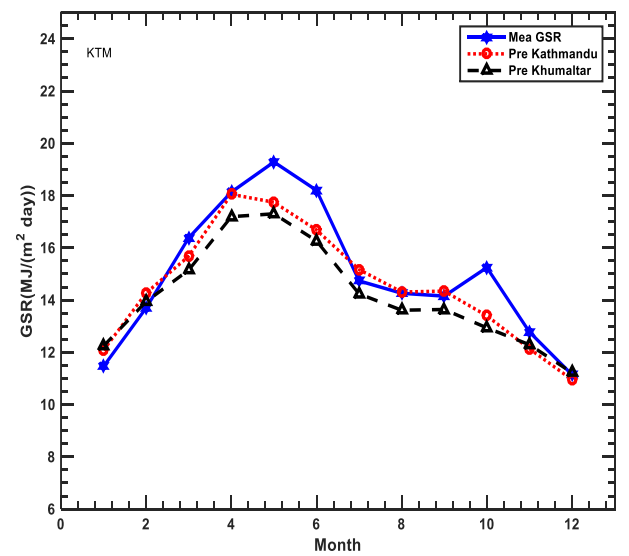

Fig. 9: Monthly variation of measured and predicted GSR for Kathmandu and Khumaltar for year 2017.

\section{Conclusion}

The maximum and minimum values of monthly average global solar radiation are found (19.29 \pm 3.91) $\mathrm{MJ} / \mathrm{m}^{2} /$ day and $(11.15 \pm 1.55) \mathrm{MJ} / \mathrm{m}^{2} /$ day in May and December, respectively. The annual average global Solar Radiation is about $14.97 \pm$ $4.49 \mathrm{MJ} / \mathrm{m}^{2} /$ day which is significant amount to operate many more energy based devices .The overall performance of parameters RMSE, MBE, MPE and $\mathrm{R}^{2}$ are found to be $1.405,0.011,-1.014$ and 0.792 , respectively in the model D. These statistical errors showed that this research work is meaningful for the estimation of global solar radiation on the basis of sunshine hour, difference of ambient temperature and relative humidity. It indicates that the estimated values of global solar radiation can be very efficiently used to compensate for the energy deficiency in the country. It concluded that the availability of global solar radiation is very encouraging from application point of view. At the end, the predicting regression coefficients could be employed for the estimation of global solar radiation at the similar climatic locations of Nepal.

\section{Acknowledgment}

Authors sincerely express deep thanks to Department of Hydrology and Meteorology (DHM), Government of Nepal for providing relevant meteorological data. Authors would like to give special thanks to R. Bachchan, P.M. Shrestha, faculty members and staffs of Dept. of Physics, Patan Multiple Campus, TU, Nepal and faculty members of Applied Sciences, IOE, Pulchowk Campus, TU. I would like to thank NAST for providing financial support to forward my research work.

\section{References}

[1] K. N. Liou, An introduction to atmospheric radiation, Academic press (2002).

[2] M. Iqbal, An introduction to solar radiation, Academic press, New York (1983). 
[3] J. A. Duffie and W.A. Beckman, Solar Engineering of Thermal Processes, John Wiley \& sons, Ins (2013).

[4] M.L. Slaby, Fundamentals of Atmosphiric Physics, Acedemic press,New York (1995).

[5] K. .N. Poudyal., Estimation of Global Solar Radiation Potential in Nepal, Ph.D.Dissertation IOE, TU (2015).

[6] D. Banjade et al., Estimation of Global Solar radiation using Empirical Models at Benevento, Italy, National Seminar on Power and Communication Sectors Development (PCSD), Kathmandu, Nepal (2010) 41-44.

[7] F. Besharat et al., Empirical models for estimating global solar radiation: A review and case study. Renewable and Sustainable Energy Reviews 21(2013)798-821.

[8] M.J. Ahmad and G.N. Tiwari, Solar radiation models-review. International journal of energy and environment 1(3) (2010) 513-532.

[9] Economic Survey 2018/19, Gov, Ministry of Finance.

[10] WECS. Water and Energy Commission Secretariat, Energy Sector Synopsis Report, Gov of Nepal (2010).

[11] J. N. Shrestha et al., Renewable energy in NepalProgress at a glance from 1998 to 2003, RETRUD03, 12-14 October, Kathmandu, Nepal, (2003).

[12] International Energy Association (2010). Key world energy statistics, International Energy Agency, Paris. (2017).

[13] A. Angstrom, Solar and terrestrial radiation, Quarterly Journal of the Royal Meteorological Society 50 (1924) 121-125.

[14] J. A. Prescott, Evaporation from a water surface in relation to solar radiation, Transactions of the Royal Society of South Australia 64 (1940) 114118.

[15] M.S. Okundamiya et al., Evaluation of various global solar radiation models for Nigeria, International Journal of Green Energy 13(5) (2016) 505- 512.

[16] C. Augustine and M. N. Nnabuchi, Relationship between Global Solar Radiation and Sunshine Hours for Calabar, Port Harcourt and Enugu, Nigeria, International Journal of Physical Sciences 4(4) (2009) 182-188.

[17] K. N. Poudyal et al., Estimation of daily global solar radiation; Nepal experience, Measurement, 46 (2013) 1807-1817.

[18] Krishna R. Adhikari et al., Estimation of global solar radiation for four selected sites in Nepal using sunshine hour, temperature and relative humidity, Journal of Power and Energy Engineering 1 (2013) 1-9.

[19] Central Bureau of Statistics, National Population and Housing Census 2011, Government of Nepal, National Planning Commission Secretariat (2012).

[20] Introduction (2018). www.kathmandu.gov.np.

[21] P. R. Pant and D. Dongal, Kathmandu Valley Profile, Kathmandu Metropolitan City (2009).

[22] Climate (2018). [Online]. www.dhm.gov.np.

[23] Kipp and Zonen, Manual CMA and CMP series, Instruction Manual, Version: the Netherlands (2006).

[24] J. L. Nayava et al., Impact of Climate, Climate Change and Modern Technology on Wheat Production in Nepal: A Case Study at Bhairahawa, Journal of Hydrology and Meteorology 6(1) (2009) $1-14$. 